Article

\title{
Experimental Study on the Performance of GFRP-GFRP Slip-Critical Connections with and without Stainless-Steel Cover Plates
}

\author{
Yang Peng ${ }^{1,2}$, Wei Chen ${ }^{1}$, Zhe $\mathrm{Wu}^{1}{ }^{1}$, Jun Zhao ${ }^{1}$ and Jun Dong ${ }^{1, *}$ \\ 1 College of Civil Engineering, Nanjing Tech University, Nanjing 211816, China; \\ yang.peng@njtech.edu.cn (Y.P.); 201761101650@njtech.edu.cn (W.C.); 662085213177@njtech.edu.cn (Z.W.); \\ 201761101656@njtech.edu.cn (J.Z.) \\ 2 Nanjing Gongda Construction Technology Co., Ltd., Nanjing 211800, China \\ * Correspondence: dongjun@njtech.edu.cn; Tel.: +86-136-0140-7837
}

Received: 3 June 2020; Accepted: 23 June 2020; Published: 26 June 2020

\begin{abstract}
Composite structures have become increasingly popular in civil engineering due to many advantages, such as light weight, excellent corrosion resistance and high productivity. However, they still lack the strength, stiffness, and convenience of constructions of fastener connections in steel structures. The most popular fastener connections in steel structures are slip-critical connections, and the major factors that influence their strength are the slip factors between faying surfaces and the clamping force due to the prevailing torque. This paper therefore examined the effect that changing the following parameters had on the slip factor: (1) replacing glass fiber reinforced plastic (GFRP) cover plates with stainless-steel cover plates; (2) adopting different surface treatments for GFRP-connecting plates and stainless-steel cover plates, respectively; and (3) applying different prevailing torques to the high-strength bolts. The impact on the long-term effects of the creep property in composite elements under the pressure of high-strength bolts was also studied with pre-tension force relaxation tests. It is shown that a high-efficiency fastener connection can be obtained by using stainless-steel cover plates with a grit-blasting surface treatment, with the maximum slip factor reaching 0.45 , while the effects of the creep property are negligible.
\end{abstract}

Keywords: GFRP composite structures; slip-critical connection; stainless-steel cover plates; surface treatment; prevailing torque

\section{Introduction}

Recently, composites have become popular as a new type of structural material used in civil engineering because they are light weight, strong, corrosion resistant, and have good designability in section shapes. However, there is still a lack of an effective connecting method in composite structures. In general, similar to steel joints, there are three schemes for composite structure joints [1]: (1) bolted, (2) adhesively bonded, and (3) combined (bolted and bonded) connections. Bolted and adhesively bonded connections each present unique benefits and characteristics. Bolted connections can be installed easily but induce severe stress concentrations. Adhesive bonds achieve good load distribution in composite connections, however, they remain vulnerable to the service temperature, humidity, and other environmental conditions. In combination joints, both adhesives and bolted connections are used, which can provide greater reliability and shear resistance but also increases the difficulty of construction. Unlike slip-critical connections, none of the connections mentioned above can provide with high strength, stiffness, good load distribution and construction convenience simultaneously.

Girão Coelho et al. [2] examined bolted connections and joints in pultruded fiber reinforced polymers and concluded that further research was necessary to improve the design of composite 
mechanically fastened joints. Unlike metal, the inherently brittle behavior (linear elasticity) of pultruded composite materials compromises its ability to yield and deform to redistribute loads, thus increasing the sensitivity to stress concentrations [3]. As a result, a large portion of current composite structural connections were inadequate because they were created by simply duplicating steel structural connections. Feo et al. [3] introduced four typologies of connections for composite structures and selected a slip-critical connection to conduct shear tests. This connection has a somewhat complicated layout, with two steel connecting plates, double pultruded fiber reinforced plastic (PFRP) cover plates, and double steel cover plates. They found that the slip factor for this type of connection can surpass 0.37 . To date, no type of effective slip-critical connection for composite structures has been proposed. Mottram et al. [4] proved that the slip factor for slip-critical connections with all composite components is relatively low, ranging from 0.14 to 0.27 , which fails to meet the application standard in civil engineering. Additionally, simple bolted assemblies for PFRP plates would lose more than $40 \%$ of the bearing capacity during their service life-time. To address these issues, Hashimoto et al. [5] added stainless-steel cover plates with a grit-blasting treatment to (glass fiber reinforced plastic) GFRP-GFRP slip-critical connections and concluded that the slip factor for this type of connection can reach 0.4 , and $86 \%$ of its strength would remain after one year under the bolt pre-tension. Stranghöner et al. [6] also examined the influence of different surface treatments in combination with austenitic stainless-steel bolting assemblies in slip-critical connections. The results demonstrated that the influence of surface treatments on the slip-resistant behavior of preloaded bolted connections with all steel elements is significant. However, little research has been dedicated to induced grit-blasting treatments for composite plates within a slip-critical connection or to the influence of cover plates. Feo et al. [3] found that applying the tightening procedure to assemblies including PFRP plates with the torque method recommended by EN1090-2 (which is for steel structural connections) led to a similar accuracy. However, insufficient data are available regarding the influence of various prevailing torques on the slip factor. Due to these disadvantages, slip-critical connections are not permitted by many composite structure design guide books, such as the American society of civil engineers (ASCE) design guide for fiber reinforced polymer (FRP) composite connections [1] and the Composites-Design Manual [7]. Studies on slip-critical connections involving composite materials are currently uncommon, and we are still far from a complete understanding of the mechanism of load transfer by friction forces with GFRP and stainless-steel faying surfaces.

In this paper, we focus on to the effects of the cover plate, surface treatment, and prevailing torque on the slip factor and long-term performance of slip-critical connections in composite structures. Shear tests and pre-tension relaxation tests were completed under quasi-static monotonic loads. Test results were presented in terms of load-displacement curve, slip load and slip factor. We performed our analysis to probe into the optimal configuration of slip-critical composite connections. Based on the adhesion theory of friction, explanations of the working mechanism of the connection are offered.

\section{Experimental Details}

\subsection{Design Procedure}

The condition of the faying surface and the bolt pre-tension force are the two main factors that influence the slip-resistant behavior of slip-critical connections in steel structures [8]. Thus, we assumed that these two factors were important parameters requiring study in regard to the connections in composite structures.

The symmetrical butt joint is the most common specimen configuration used in slip-critical connections. There are three configurations of butt joints proposed by different standards. EN 1090-2 specifications [9] suggest a standard test specimen with two cover plates, four slip planes, and four high-strength bolts. The Research Council on Structural Connections (RCSC) specifications [10] suggest a standard test specimen with two cover plates, two slip planes, and one high-strength bolt. The AS 4100 specifications [11] suggest a standard test specimen with two cover plates, four slip 
planes, and two high-strength bolts. Through a thorough literature review, we determined that the standard specimen proposed by the EN1090-2 specifications is the most popular [12]. However, despite its common use, this standard specimen is unsuitable for the engineering practice of slip factor measurements. By considering the convenience of the assembly and ease of measurement, the butt joint test specimen proposed by the AS 4100 specifications [11] was chosen for the purposes of this study.

\subsection{Specimen Configuration}

\subsubsection{Geometrical Size and Mechanical Properties}

The connecting components were composed of GFRP plates, which were $300 \mathrm{~mm} \times 40 \mathrm{~mm} \times 6 \mathrm{~mm}$, the bolt-hole diameter $D$ was $8 \mathrm{~mm}$, and the hole center was $60 \mathrm{~mm}$ from the end of the plate. The bolt hole diameter and bolt hole spacing selection were based on American Society of Civil Engineers design guide for FRP composite connections [1]. The GFRP plates were made via a pultrusion process. The fiber volume fraction was $40 \%$. The fiber was oriented at angles of $45^{\circ} / 90^{\circ} / 0^{\circ}$. All the information was provided by the manufacturers. The austenitic stainless-steel 304 plates measured $205 \mathrm{~mm} \times 40 \mathrm{~mm} \times 5 \mathrm{~mm}$, the bolt-hole diameter $D$ was $8 \mathrm{~mm}$, and the center of the hole was $40 \mathrm{~mm}$ from the end of the plate. The mechanical properties of the plates are presented in Table 1 . The mechanical properties of the stainless-steel plates and those of the GFRP plates were based on the technical data provided by the manufacturers. The washer had an outer diameter $D_{0}$ of $14 \mathrm{~mm}$ and an inner diameter $d_{0}$ of $6 \mathrm{~mm}$. The material of the high-strength bolt was stainless-steel, grade A4-80, with a nominal diameter of $6 \mathrm{~mm}$. The size of the test specimen is shown in Figure 1.

Table 1. Mechanical properties of plates.

\begin{tabular}{cccc}
\hline Materials & Tensile Strength (MPa) & Elastic Modulus (GPa) & ${\text { Vickers Hardness (kgf/mm }{ }^{\mathbf{2}} \text { ) }}$ \\
\hline Glass fiber reinforced plastic (GFRP) & 300 & 15 & $/$ \\
Austenitic stainless-steel 30408 & 515 & 193 & 140 \\
\hline
\end{tabular}

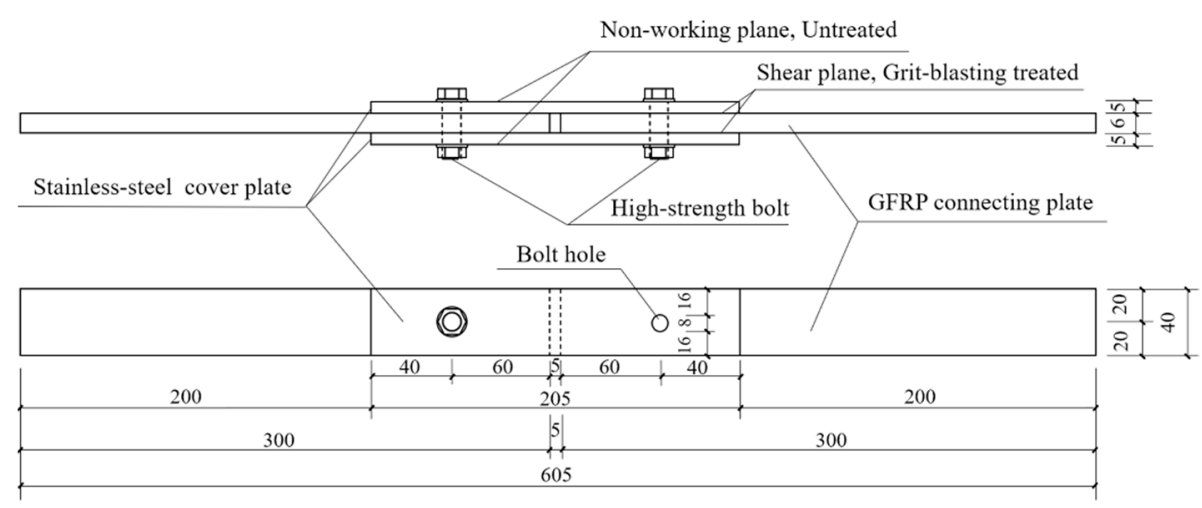

Figure 1. Specimen size (unit:mm).

\subsubsection{Surface Preparation}

A grit-blasting treatment was introduced in our tests to increase the surface hardness and roughness. Using compressed air, a high-speed jet of air was formed, which sprayed abrasives at high speed onto the surface of the specimen to be treated. The impact and cutting action of the abrasives helped to clean the surface to a certain degree, change the roughness, and enhance the mechanical properties. It was determined that the grit-blasting caused an increase in the Vickers micro-hardness values of all of the materials, which led to an increase in the ultimate tensile strength [13]. Based on the tribological theory, the friction factor can increase with the increment of the surface roughness and strength [14]. The surfaces of the test specimens were treated by grit-blasting using a HZ-1616r-1 sand blaster. The key parameters of the grit-blasting treatment are listed in Table 2. 
Table 2. Main parameters of the grit-blasting treatment.

\begin{tabular}{cccccc}
\hline Blasting Treatment & Abrasives Type & Nozzle Pressure (bar) & Blasting Angle $\left({ }^{\circ}\right)$ & Distance of Spray Gun (mm) & Blasting Time (s) \\
\hline Manual & Brown corundum & 8 & 90 & 100 & 30 \\
\hline
\end{tabular}

The grit-blasting treatment was carried out on the stainless-steel plate using \#24 grit and \#60 grit abrasive according to Kobayashi et al. [15]. The numbers \#24 and \#60 represent the size of the abrasive, the higher the number, the smaller the grit size and the smoother the surface will be after blasting [13]. Therefore, the surface roughness of the stainless-steel plates treated with the \#24 grit abrasive will be greater than that of the stainless-steel plates treated with \#60 grit abrasive. The different surface conditions captured by commercial camera under daylight are presented in Figure 2. When the surfaces of the plates become rougher, the diffuse reflection ratio on the surface will increase, and the mirror reflection ratio will decrease. Therefore, under the same light source, the visual perception of brightness is different, and the rougher the surface, the dimmer the appearance [16]. The blasting time for the GFRP plate should be reasonably controlled to prevent initial damage. The surface of the untreated GFRP plate was left in its original state, while the surface of the GFRP plate treated with the grit abrasive was glossy and somewhat rough.

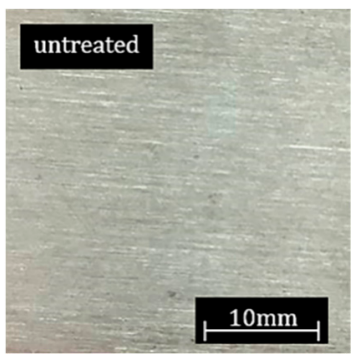

(a)

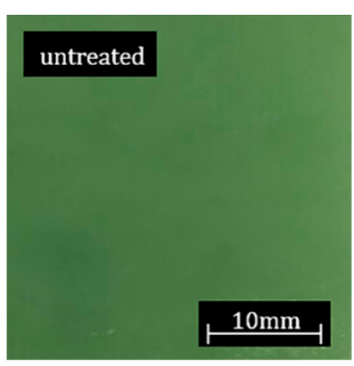

(d)

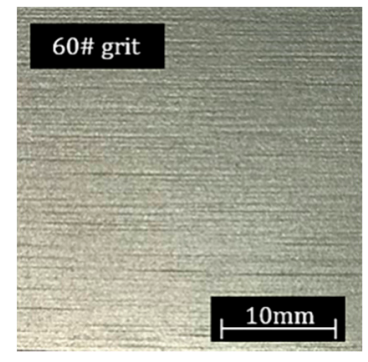

(b)

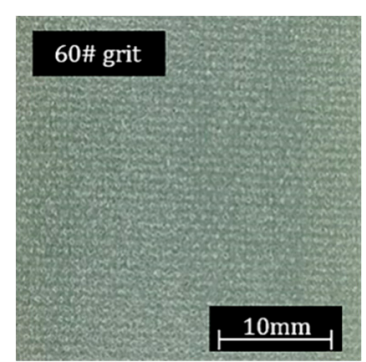

(e)

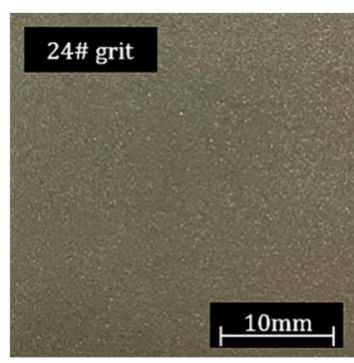

(c)

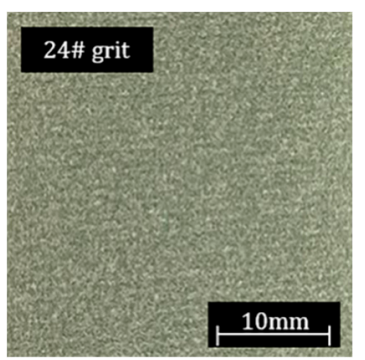

(f)

Figure 2. Plate surfaces with and without grit-blasting treatment. (a) Untreated stainless-steel surface; (b) stainless-steel surface treated with 60\# grit-blasting; (c) stainless-steel surface treated with 24\# grit-blasting; (d) untreated GFRP surface; (e) GFRP surface treated with 60\# grit-blasting; (f) GFRP surface treated with $24 \#$ grit-blasting.

When implementing the grit-blasting treatment, only the faying planes were treated, and the non-working planes contacting bolt washers remained untreated, as shown in Figure 1. Several combinations of connecting methods were developed in this paper and their abbreviations are listed in Table 3. The optimal matching method of various connections were predicted. 
Table 3. Abbreviations for each connection method.

\begin{tabular}{ccc}
\hline $\begin{array}{c}\text { Material of Connecting Plates } \\
\text { (Surface Treatment) }\end{array}$ & Material of Cover Plates (Surface Treatment) & Abbreviation of Connection Methods \\
\hline GFRP (untreated) & GFRP (untreated) & G-G \\
GFRP (untreated) & Stainless-steel (untreated) & G-S \\
GFRP (untreated) & Stainless-steel (\#60 grit blasting) & G-S60\# \\
GFRP (untreated) & Stainless-steel (\#24 grit blasting) & G-S24\# \\
GFRP (\#60 grit blasting) & Stainless-steel (\#24 grit blasting) & G60\#-S24\# \\
\hline
\end{tabular}

\subsection{Slip Load Definition and Slip Factor Calculation}

The load-displacement curve was calculated upon conclusion of the tests. The slip load was defined according to this curve. In the specifications given by the RCSC, the load-displacement curves can be classified into three types [10], as shown in Figure 3. Failure of a slip-critical connection is defined at different levels of slip according to the load-displacement curve type acquired by shear tests [17]. Examining the load-displacement curves, (a) is the type of curve where the slip load occurs at the maximum load. There is a drop in the load after the slip load. This drop in load is related to the major slip [2] and the drop marks the failure of the connection. Next, (b) is the type of curve where the slip load becomes an inflection point and changes suddenly, and the inflection point is also the failure point of the connection. Finally, (c) is the type of curve where the slip rate changes gradually. In this case, the slip load and failure point are a same fixed point, at which the slip equals 0.02 in $(\sim 0.5 \mathrm{~mm})$. In this type of curve, minor slippage occurs before the slip load [2].

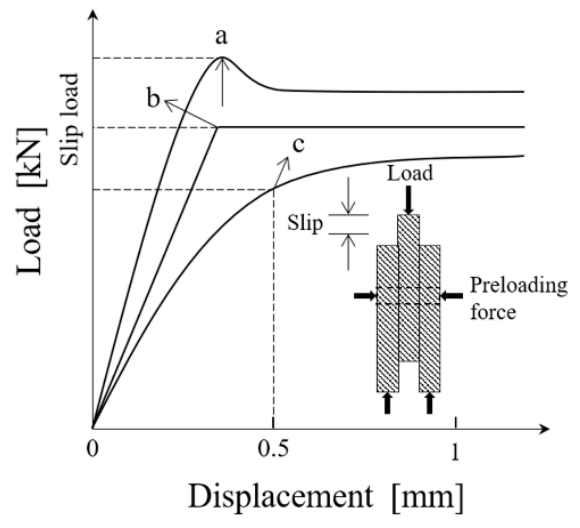

Figure 3. Three types of slip load curves [10].

Referring to the Chinese technical specification for stainless-steel structures (CECS 410) [18], the slip factor, $\mu$, is calculated according to the following formula:

$$
\mu=\frac{F}{n_{f} \sum_{i=1}^{m} P_{i}}
$$

where, $F$ is the slip load; $n_{f}$ is the number of friction planes; $m$ is the number of high-strength bolts; and $P_{i}$ is the pre-tension force of the high-strength bolts, calculated using Formula (2).

The Chinese standard JGJ82-2011 [19] provides the details of the torque-tension relationship when tightening high-strength bolt assemblies.

$$
T=k d P
$$

where, $T$ is the torque applied to the nut, $k$ is the torque coefficient, $d$ is the nominal bolt diameter, and $P$ is the specified bolt preload. If the high-strength bolts adopt the same value of torque coefficient, the required pre-tension can be obtained by applying a certain amount of torque to the bolt. 


\subsection{Shear Tests}

\subsubsection{Experimental Setup and Specimen Assembly}

According to the Chinese standard, JGJ82-2011 [19], the value of the torque coefficient $k$ of the high-strength bolts ranged from 0.11 to 0.15 . The torque coefficient $k$ of the stainless-steel A4- 80 high strength bolts was 0.15 according to Chen et al. [20]. The diameter of the high strength bolt was $6 \mathrm{~mm}$. According to ISO3506-1:2009 [21], the torque limit of M6 stainless-steel A4-80 high-strength bolts was $15 \mathrm{~N} \mathrm{~m}$. However, due to the low stiffness and strength of the GFRP plates, a prevailing torque higher than $15 \mathrm{~N} \cdot \mathrm{m}$ may lead to the excessive pre-tensioning of the bolts, subsequently damaging the GFRP plate during the bolt tensioning process [22]. The value recommended by the authors in [23] was used to pre-tension the bolts, and the prevailing torque $T$ was $7 \mathrm{~N} \cdot \mathrm{m}$, insuring a level of shear resistance and avoiding initial damage to the components. The values of the bolt preloading force and prevailing torque were listed in Table 4.

Table 4. Test parameters of the high strength bolt.

\begin{tabular}{ccccc}
\hline Type of Bolt & $\begin{array}{c}\text { Diameter } \\
\boldsymbol{d}(\mathbf{m m})\end{array}$ & $\begin{array}{c}\text { Preloading Force } \\
\boldsymbol{P}(\mathbf{k N})\end{array}$ & $\begin{array}{c}\text { Torque Coefficient } \\
\boldsymbol{k}\end{array}$ & $\begin{array}{c}\text { Prevailing Torque } \\
\boldsymbol{T}(\mathbf{N} \cdot \mathbf{m})\end{array}$ \\
\hline A4-80 & 6 & 7.78 & 0.15 & 7 \\
\hline
\end{tabular}

A UTM5305 microcomputer-controlled electro-hydraulic servo universal testing machine was chosen to perform the shear tests, as the machine could firmly clamp the specimen with hydraulic fixtures and the maximum output load could reach $300 \mathrm{kN}$. The specimens were assembled first, and then clamped vertically into the fixture of the electronic universal testing machine, and the axis of the specimen was strictly aligned with the fixture center, as shown in Figure 4 . The test specimens had tension applied monotonically with a speed of $2 \mathrm{~mm} / \mathrm{min}$. The tests stopped once the applied tension sharply increased. The load and displacement were recorded synchronously with a data acquisition system.

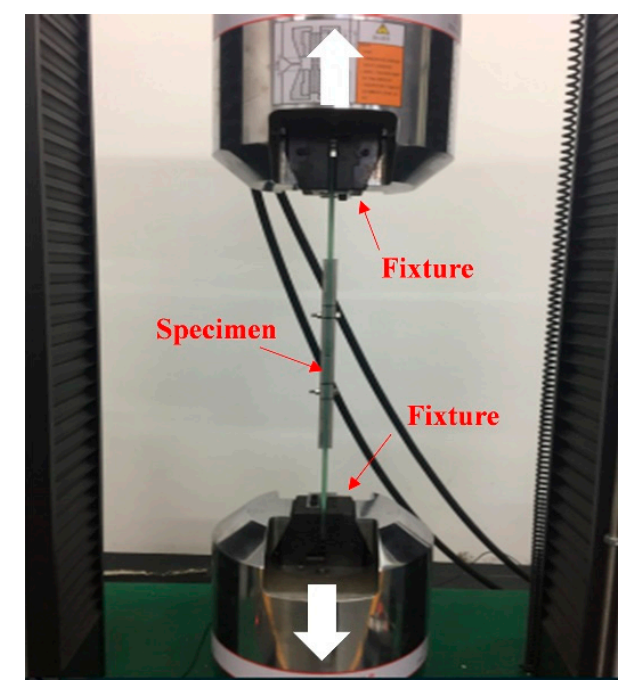

Figure 4. Loading equipment and testing setup.

\subsubsection{Test Variables}

In order to evaluate the influence of the prevailing torque and surface characteristics of the test plates on the slip factor, the following variables were focused on:

(1) The hardness of the plate surface. The hardness of the stainless-steel plate is much higher than that of the GFRP plate. We hypothesized that the higher hardness could help achieve a higher 
slip factor. Two configurations of the plates were used to study the maximum slip factor: (a) a butt joint of two GFRP plates with GFRP cover plates, and (b) a butt joint of two GFRP plates with stainless-steel cover plates.

(2) The roughness of the plate surface. The roughness of the plate surface after grit-blasting was different depending on the grit of the abrasive used. Different slip factors can be achieved depending on the surface roughness. The $\# 24$ and $\# 60$ grit abrasives were chosen for this study. The surface roughness caused by the \#24 grit abrasive was higher than that caused by the \#60 grit abrasive. To avoid initial surface damage, the low hardness GFRP plates were only blasted with the \#60 grit abrasive.

(3) The prevailing torque. Creep deformation can occur in GFRP plates when they are under a high constant pressure. The creep deformation can reduce the friction capacity of the GFRP plate exposed to this pressure. Based on tribology, the slip factor may be influenced by the pressure on the friction plane. The prevailing torque determines the pre-tension for high-strength bolts. We expected that the pre-tension could influence the contact pressure on the friction planes of butt joints. Therefore, the prevailing torque can be an important influence factor on the slip factor of slip-critical connections. When it appears as a variable, the prevailing torque used was $5 \mathrm{~N} \cdot \mathrm{m}$, $6 \mathrm{~N} \cdot \mathrm{m}, 7 \mathrm{~N} \cdot \mathrm{m}, 8 \mathrm{~N} \cdot \mathrm{m}, 9 \mathrm{~N} \cdot \mathrm{m}$, and $10 \mathrm{~N} \cdot \mathrm{m}$, respectively (in other shear tests, the prevailing torque used was a constant $7 \mathrm{~N} \cdot \mathrm{m}$ ).

To study these variables, we performed shear tests for 6 sets of 22 specimens. The specimens and corresponding parameters are listed in Table 5.

Table 5. Specimens in the shear tests.

\begin{tabular}{ccccc}
\hline $\begin{array}{c}\text { Connection } \\
\text { Methods }\end{array}$ & $\begin{array}{c}\text { Connecting Plate Materials } \\
\text { (Surface Treatment) }\end{array}$ & $\begin{array}{c}\text { Cover Plate Materials } \\
\text { (Surface Treatment) }\end{array}$ & $\begin{array}{c}\text { Prevailing Torque } \\
\boldsymbol{T} \text { (N-m) }\end{array}$ & Specimen \\
\hline G-G & GFRP (untreated) & GFRP (untreated) & 7 & G-G-1/2 \\
\hline G-S & GFRP (untreated) & Stainless-steel (untreated) & 7 & G-S-1/2 \\
\hline G-S60\# & GFRP (untreated) & Stainless-steel (\#60 grit blasting) & 7 & G-S60\#-1/2 \\
\hline G-S24\# & GFRP (untreated) & Stainless-steel (\#24 grit blasting) & 7 & G-S24\#-1/2 \\
\hline G60\#-S24\# & GFRP (\#60 grit blasting) & Stainless-steel (\#24 grit blasting) & 7 & G60\#-S24\#-1/2 \\
\hline & & & 5 & T-5-1/2 \\
G-S24\# & & & 6 & T-6-1/2 \\
& GFRP (untreated) & Stainless-steel (\#24 grit blasting) & 8 & T-7-1/2 \\
& & & 9 & T-8-1/2 \\
& & & T-9-1/2 & T-10-1/2 \\
\hline
\end{tabular}

\subsection{Pre-Tension Force Relaxation Tests}

GFRP has a creep property [24], that is, when two GFRP plates are subjected to bolt pre-tension forces for a period of time, a stress relaxation occurs in the GFRP. This leads to a continuous reduction in the bolt pre-tension force, resulting in a reduction in the friction capacity and strength of the slip-critical connections. Therefore, it is necessary to examine the effect of the creep deformation of GFRP plates on the strength of the slip-critical connections.

We conducted 2 sets of tests containing 16 specimens. The first test carried out was a standing treatment of the G-G connection and G-S24\# connection over different time periods. Then, shear tests were carried out to verify the effect of the creep deformation of the GFRP plates on the strength by examining the residual ratio of the slip load. The assembled test specimens were left to stand for 1 day, 7 days, and 30 days before the subsequent tests. The bolt pre-tension relaxation tests and shear tests were conducted in May and June at Nanjing, China. Before the shear tests, specimens were left to stand in a dry indoor environment and the room temperature was between 19 and $26^{\circ} \mathrm{C}$. The temperature fluctuation in this range would not influence the mechanical properties of GFRP materials according to [25]. The specimens are listed in Table 6. 
Table 6. Specimens in the pre-tension force relaxation tests.

\begin{tabular}{ccccc}
\hline $\begin{array}{c}\text { Connection } \\
\text { Methods }\end{array}$ & $\begin{array}{c}\text { Connecting Plate Materials } \\
\text { (Surface Treatment) }\end{array}$ & $\begin{array}{c}\text { Cover Plate Materials } \\
\text { (Surface Treatment) }\end{array}$ & $\begin{array}{c}\text { Relaxation Time } \\
\text { (Days) }\end{array}$ & Specimen \\
\hline & & & 0 & A-0-1/2 \\
G-G & GFRP (untreated) & GFRP (untreated) & 1 & A-1-1/2 \\
& & & 7 & A-7-1/2 \\
& & & 30 & A-30-1/2 \\
\hline \multirow{3}{*}{ G-S24\# } & GFRP (untreated) & Stainless-steel (\#24 grit & 1 & B-0-1/2 \\
& & blasting) & 7 & B-1-1/2 \\
& & & 30 & B-7-1/2 \\
& & & \\
\hline
\end{tabular}

\section{Results and Discussion}

\subsection{The Effects of Cover Plates}

The slip factors and slip loads are listed in Table 7. Two sets of tests were performed, as shown in the table. Each kind of test was repeated two times using two identical specimens to grant the reliability of the tests. The load-displacement curves of the two tests series are shown in Figure 5 . The load-displacement curve of the G-S connection can be described by the (c) type curve from Figure 3 . The load-displacement curve of the G-G connection can be described by the (b) type curve from Figure 3 . The initial stiffness of the G-S curve was larger than that of the G-G curve. These characteristics can be explained by the adhesion theory of friction [26]. The friction force consists of two components, namely adhesion and deformation [26]. The adhesion force is the rupture resistance of the junctions, which is induced between the two contact surfaces. The deformation force is the resistance that is caused by the plastic deformation of interlocking asperities when the contact surfaces slide with each other. In the G-G connection test, the connecting plates and cover plates are all GFRP, the hardness is the same, and one side cannot be embedded into the other. The asperities on the surface of the GFRP plates were in an elastic contact state. The deformation of asperities in polymers is primarily elastic. The amount of the junction induced by the plastic deformation of the asperities was small. Thus, barely no scratches were formed after shear tests and only minor plastic deformation points could be seen, as shown in Figure 6. The significant proportion of the friction force with polymers came from the deformation force [26]. The surface of the stainless-steel plate was harder than that of the GFRP plate. The asperities on the surface of the stainless-steel could penetrate and plough into the GFRP surface, which produced grooves if the shear strength of the GFRP was exceeded. In Figure 5, the load-displacement curve of the G-S connection was above the curve of the G-G connection. This is due to the larger deformation force of the G-S connection.

Table 7. The slip load and slip factor values of tested connections with different cover plates.

\begin{tabular}{ccc}
\hline Specimen & Slip Load $\boldsymbol{F} \mathbf{( k N )}$ & Slip Factor $\boldsymbol{\mu}$ \\
\hline G-G-1 & 2.64 & 0.17 \\
G-G-2 & 2.78 & 0.18 \\
Average value & 2.71 & 0.18 \\
\hline G-S-1 & 3.16 & 0.20 \\
G-S-2 & 3.17 & 0.20 \\
Average value & 3.17 & 0.20 \\
\hline
\end{tabular}




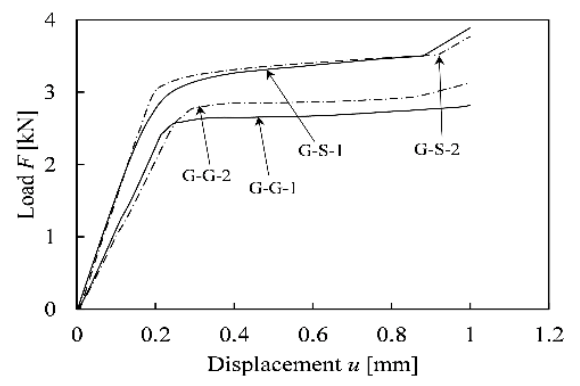

Figure 5. The load-displacement curves of specimens with different cover plates.

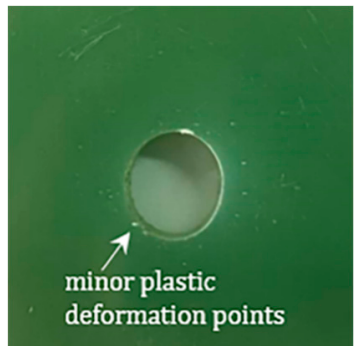

(a)

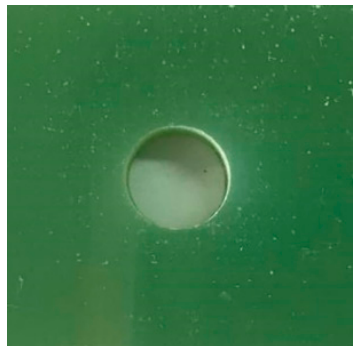

(b)

Figure 6. Plate surfaces of G-G connection after shear test. (a) GFRP connecting plate surface after shear test; (b) GFRP cover plate surface after shear test.

According to Bhushan [26], the friction factor, $\mu_{\mathrm{a}}$, of the adhesion force with polymers can be represented by the following equation:

$$
\mu_{a}=\frac{\tau_{0}}{p}+\alpha
$$

where, $\tau_{0}$ is the shear strength of the polymers, $p$ is the contact pressure on the actual contact area, $\alpha$ is a constant, and the value of $\alpha$ for polymers is 0.2 . In the polymers, the $\tau_{0} / p$ is much smaller than $\alpha$ [26], the friction factor can be approximately 0.2 when the deformation force is ignored. The experimental average value of the slip factor with a G-G connection was 0.18 , which is close to 0.2 . This demonstrates that the deformation component can be ignored in G-G connections. The average value of the slip factor with G-S connections was larger than that of the G-G connections. This is related to the higher deformation force, as explained above.

\subsection{The Effects of the Grit-Blasting Surface Treatment}

Three sets of nine specimens were applied with shear tests. The slip load and slip factor values acquired are shown in Table 8. The load-displacement curves obtained from the shear tests of each connection method are shown in Figure 7. The load-displacement curve of the G60\#-S24\# connection in Figure 7 can be described by the typical (b) type curve from Figure 3. The specimen showed a gradual change in the load as the displacement was increased. The load-displacement curves of the G-S24\# and G-S60\# connections in Figure 7 can be described by the (a) type curve in Figure 3. These two types of specimen showed a major slip and reduction in the load. The reduction rate of the load with the G-S24\# connection specimens was much larger than that of the G-S60\# connection specimens. The slip load increased with the increase in the grit size (from \#60 to \#24). As previously explained, the main component of the friction force with the GFRP connections is likely the deformation force. The grit-blasting surface treatment increases the number of asperities and roughness on the faying surface of stainless-steel cover plate. The deformation force increased with the increase in the number of asperities and the roughness of the harder stainless-steel cover plate. The asperities on the surface of the stainless-steel could penetrate and plough into the GFRP surface, which produced grooves if the shear strength of the GFRP was exceeded. As is shown in Figure 8, the grooves were formed 
on the GFRP connecting plate and the GFRP powder ploughed by embedded asperities were left on the stainless-steel cover plate surface. A load drop did not occur in the load-displacement curve of the G60\#-S24\# connection compared to the load-displacement curves of the G-S24\# and G-S60\# connections, which may be related to the ratchet mechanism [26]. The ratchet mechanism describes a situation where two rough surfaces contact each other and plastic deformations do not happen. The asperities of one mating surface climb up and down on the other mating surface. The motion mode of the ratchet mechanism resembles a Coulomb friction model. The roughness of the surface of the GFRP plate increased after being treated by grit-blasting. The rough surface of the GFRP plate contacted the rough surface of the stainless-steel plate and the asperities being produced under contact stress elastically deformed. The ratchet mechanism appeared in the G60\#-S24\# connection, which accounts for the maintenance of the connection bearing capacity. As shown in Figure 9, barely any trace could be found after the shear test due to the ratchet mechanism that is elastic deformation of the asperities recovered after unloading.

Table 8. The slip load and slip factor values of the tested connections with different grit-blasting treatments.

\begin{tabular}{ccc}
\hline Specimen & Slip Load $\boldsymbol{F}(\mathbf{k N})$ & Slip Factor $\boldsymbol{\mu}$ \\
\hline G-S60\#-1 & 5.72 & 0.37 \\
G-S60\#-2 & 5.73 & 0.37 \\
Average value & 5.73 & 0.37 \\
\hline G-S24\#-1 & 6.48 & 0.42 \\
G-S24\#-2 & 6.42 & 0.41 \\
Average value & 6.45 & 0.42 \\
\hline G60\#-S24\#-1 & 6.75 & 0.43 \\
G60\#-S24\#-2 & 6.72 & 0.43 \\
Average value & 6.74 & 0.43 \\
\hline
\end{tabular}

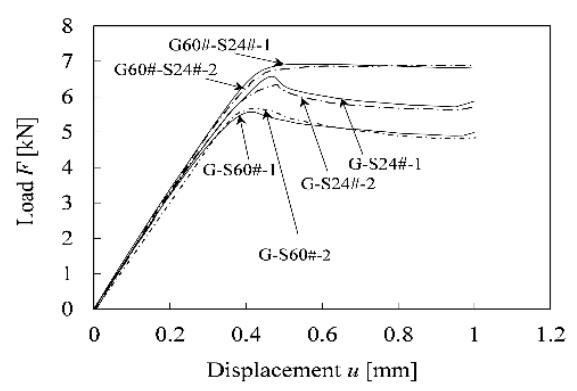

Figure 7. The load-displacement curves of specimens with different grit-blasting surface treatments.

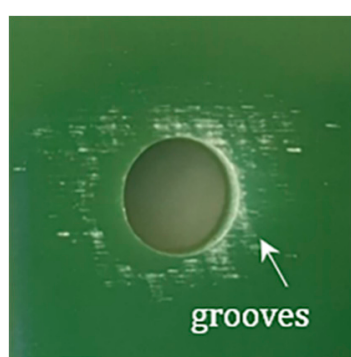

(a)

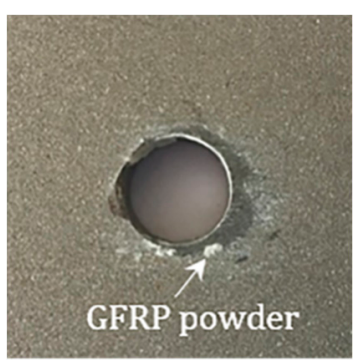

(b)

Figure 8. Plate surfaces of G-S24\# connection after shear test. (a) GFRP connecting plate surface after shear test; (b) stainless-steel cover plate surface after shear test. 


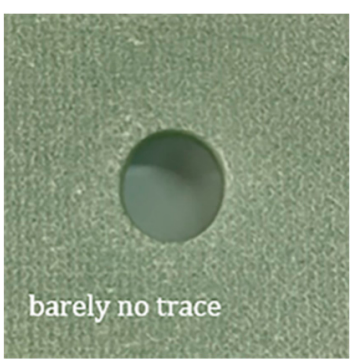

(a)

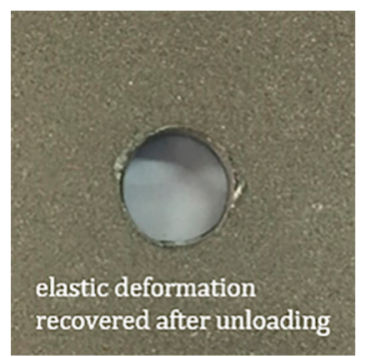

(b)

Figure 9. Plate surfaces of G60\#-S24\# connection after shear test. (a) GFRP connecting plate surface after shear test; (b) stainless-steel cover plate surface after shear test.

The slip factor of the G60\#-S24\# connection was the highest and the slip factor of the G-S60\# connection was the lowest among the three connection types. The difference between the slip factors of three connections was minimal. Hashimoto et al. [5] tested the GFRP slip-critical connection with stainless-steel cover plates. In their experiments, the surfaces of stainless-steel cover plates were treated by grit-blasting. They found that the slip factor was 0.449 . This value is close to the results from our tests, as listed in Table 8. Feo et al. [3] found that the slip factor value of the GFRP slip-critical connection with structural-steel cover plates was around 0.37 , which is again similar to the results of our tests. It is clear that increasing the roughness of the faying surface using a grit-blasting treatment is a valid way to increase the slip load of GFRP slip-critical connections. The slip factor of the G60\#-S24\# slip-critical connection was slightly higher than that of the G-S24\# slip-critical connection, indicating that grit-blasting treatment for GFRP plates was not greatly efficient or economic when stainless-steel plates were already blast treated. The grit-blasting treatment may damage the surface of the GFRP plates, therefore we do not propose any grit-blasting treatment for the GFRP plates.

\subsection{The Effects of Prevailing Torque}

Based on the phenomenon and analysis above, the G-S24\# connection was proven to be the optimal configuration with both efficient shear resistance and economy. As a result, the G-S24\# connection only was selected to examine the influence of the prevailing torque on the slip factor of slip-critical connections. The prevailing torques used in the tests were $5 \mathrm{~N} \cdot \mathrm{m}, 6 \mathrm{~N} \cdot \mathrm{m}, 7 \mathrm{~N} \cdot \mathrm{m}, 8 \mathrm{~N} \cdot \mathrm{m}, 9 \mathrm{~N} \cdot \mathrm{m}$, and $10 \mathrm{~N} \cdot \mathrm{m}$. Each set of tests was performed with two identical specimens. The slip load and slip factor are listed in Table 9 and the load-displacement curves are shown in Figure 10. The load-displacement curves of the G-S24\# connection with different prevailing torques in Figure 10 can be described by the (a) type curve from Figure 3. These curves are similar to the load-displacement curve of the G-S24\# connection from Figure 7.

Table 9. The slip load and factor values of tested connections with different prevailing torques.

\begin{tabular}{|c|c|c|c|c|c|c|c|}
\hline Specimen & $\begin{array}{c}\text { Prevailing } \\
\text { Torque } T(\mathrm{~N} \cdot \mathrm{m})\end{array}$ & $\begin{array}{l}\text { Slip Load } \\
\quad F(\mathbf{k N})\end{array}$ & $\begin{array}{l}\text { Average } \\
\text { Value }\end{array}$ & $\begin{array}{l}\text { Growth Rate } \\
\text { Compared with the } \\
\text { Former }(\%)\end{array}$ & $\begin{array}{l}\text { Slip } \\
\text { Factor } \mu\end{array}$ & $\begin{array}{l}\text { Average } \\
\text { Value }\end{array}$ & $\begin{array}{c}\text { Growth Rate } \\
\text { Compared with the } \\
\text { Former }(\%)\end{array}$ \\
\hline $\begin{array}{l}\mathrm{T}-5-1 \\
\mathrm{~T}-5-2\end{array}$ & 5 & $\begin{array}{l}4.90 \\
4.94\end{array}$ & 4.92 & I & $\begin{array}{l}0.44 \\
0.44\end{array}$ & 0.44 & / \\
\hline $\begin{array}{l}\mathrm{T}-6-1 \\
\mathrm{~T}-6-2\end{array}$ & 6 & $\begin{array}{l}5.93 \\
5.85\end{array}$ & 5.89 & 19.72 & $\begin{array}{l}0.45 \\
0.44\end{array}$ & 0.45 & 2.27 \\
\hline $\begin{array}{l}\mathrm{T}-7-1 \\
\mathrm{~T}-7-2\end{array}$ & 7 & $\begin{array}{l}6.37 \\
6.43\end{array}$ & 6.40 & 8.66 & $\begin{array}{l}0.41 \\
0.41\end{array}$ & 0.41 & -8.89 \\
\hline $\begin{array}{l}\mathrm{T}-8-1 \\
\mathrm{~T}-8-2\end{array}$ & 8 & $\begin{array}{l}6.78 \\
6.77\end{array}$ & 6.78 & 5.94 & $\begin{array}{l}0.39 \\
0.39\end{array}$ & 0.39 & -4.88 \\
\hline $\begin{array}{l}\mathrm{T}-9-1 \\
\mathrm{~T}-9-2\end{array}$ & 9 & $\begin{array}{l}7.13 \\
7.05\end{array}$ & 7.09 & 4.57 & $\begin{array}{l}0.36 \\
0.35\end{array}$ & 0.36 & -7.69 \\
\hline $\begin{array}{l}\mathrm{T}-10-1 \\
\mathrm{~T}-10-2\end{array}$ & 10 & $\begin{array}{l}7.39 \\
7.43\end{array}$ & 7.41 & 4.51 & $\begin{array}{l}0.33 \\
0.33\end{array}$ & 0.33 & -8.33 \\
\hline
\end{tabular}




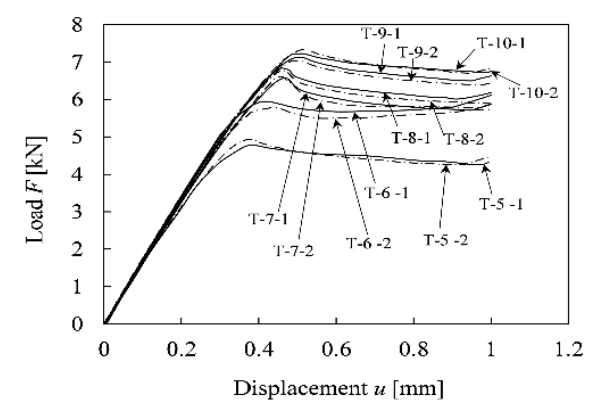

Figure 10. The load-displacement curves of connections with different prevailing torques.

From Table 8, it was clear that as the prevailing torque was increased, the slip load of the connections increased gradually, and the slip factor slightly decreased. Each time the prevailing torque was increased, the slip load also increased, however, the magnitude of the increment was lessened each time. Lacey et al. [12] demonstrated that the slip factor decreased with an increase in contact pressure in steel-steel connections. They explained that the surface asperities were flattened by the applied contact pressure, which decreased the deformation component of the friction force.

\subsection{The Effects of Pre-Tension Force Relaxation}

The GFRP plates experience a creep deformation under sustained loads [27]. When a GFRP plate is subjected to the preloading force of high-strength bolts during the service period, creep deformation is induced, and the pre-tension force of the high-strength bolts should relax. The slip load decreases as the pre-tension force is relaxed [17]. Table 10 summarizes the variation in the results of the G-G slip-critical connection, and the G-S24\# slip-critical connection was due to the creep deformation of the GFRP plates. We found that the slip load decreased as the preloading time increased in both connections. The residual rate of the shear resistance of the G-S24\# connection was much higher than that of the G-G connection. After one day of preloading time, the slip load of the G-S24\# slip-critical connection decreased by $6 \%$. After 30 days, it decreased by only $9 \%$. The test results showed that compared to the G-G connection, the G-S24\# connection still had good slip resistance, even after a long period of preloading time.

Table 10. Slip load variation under the pre-tension of high-strength bolts.

\begin{tabular}{|c|c|c|c|c|c|}
\hline $\begin{array}{l}\text { Connection } \\
\text { Methods }\end{array}$ & Specimen & $\begin{array}{l}\text { Preloading } \\
\text { Time (day) }\end{array}$ & $\underset{(\mathbf{k N})}{\text { Slip Load } F}$ & $\begin{array}{l}\text { Average Value } \\
(\mathbf{k N})\end{array}$ & $\begin{array}{c}\text { Residual Rate } \\
(\%)\end{array}$ \\
\hline \multirow{4}{*}{ G-G } & $\begin{array}{l}A-0-1 \\
A-0-2\end{array}$ & 0 & $\begin{array}{l}2.95 \\
2.64\end{array}$ & 2.78 & / \\
\hline & $\begin{array}{l}A-1-1 \\
A-1-2\end{array}$ & 1 & $\begin{array}{l}2.40 \\
2.44\end{array}$ & 2.42 & 87 \\
\hline & $\begin{array}{l}A-7-1 \\
A-7-2\end{array}$ & 7 & $\begin{array}{l}2.36 \\
2.28\end{array}$ & 2.32 & 83 \\
\hline & $\begin{array}{l}A-30-1 \\
A-30-2\end{array}$ & 30 & $\begin{array}{l}2.17 \\
2.23\end{array}$ & 2.20 & 79 \\
\hline \multirow{4}{*}{ G-S24\# } & $\begin{array}{l}\text { B- } 0-1 \\
\text { B- } 0-2\end{array}$ & 0 & $\begin{array}{l}6.32 \\
6.26\end{array}$ & 6.29 & l \\
\hline & $\begin{array}{l}\text { B-1-1 } \\
\text { B-1-2 }\end{array}$ & 1 & $\begin{array}{l}5.82 \\
5.94\end{array}$ & 5.88 & 94 \\
\hline & $\begin{array}{l}\text { B-7-1 } \\
\text { B-7-2 }\end{array}$ & 7 & $\begin{array}{l}5.79 \\
5.73\end{array}$ & 5.76 & 92 \\
\hline & $\begin{array}{l}\text { B-30-1 } \\
\text { B-30-2 }\end{array}$ & 30 & $\begin{array}{l}5.72 \\
5.68\end{array}$ & 5.70 & 91 \\
\hline
\end{tabular}


Kobayashi et al. [15] performed bolt pre-tension relaxation tests for up to half a year to investigate the slip load reduction of GFRP slip-critical connections with steel cover plates. The configuration of the G-S24\# connection in our paper is similar to that of Kobayashi's results [15]. The residual rate of slip load from Kobayashi's tests [15] and our own tests are presented in Figure 11. From this figure, the G-G connection would lose more than $20 \%$ of shear resistance within a month. The residual rate curve's decreasing rate of slip load of the G-S24\# connection was lower than that of Kobayashi's tests within 30 days, and the downward trend seemed to be stable. The slip load in Kobayashi's tests [15] dropped $16 \%$ after half a year. Therefore, we speculate that the slip load of the G-S24\# connection would be reduced by no more than $16 \%$ after standing for half a year, retaining the vast majority of its original bearing capacity.

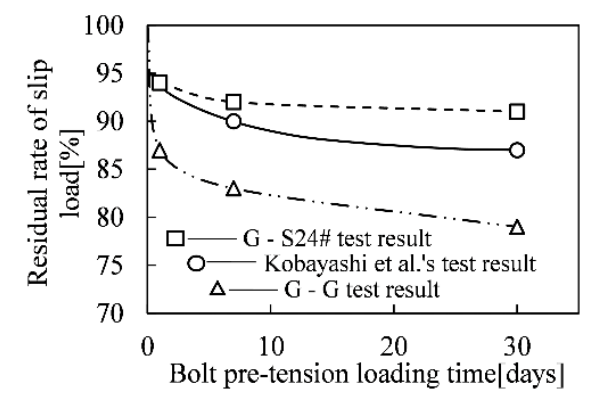

Figure 11. Comparison of the slip load residual rate after the bolt pre-tension relaxation tests.

\section{Conclusions}

We conducted 22 shear tests with different cover plates, prevailing torques, and grit-blasting surface treatments, and we investigated the slip load and slip factor of the GFRP-GFRP slip-critical connections. We conducted 16 pre-tension force relaxation tests. The long-term performance of the GFRP-GFRP slip-critical connections was investigated. An explanation of the force transformation mechanism of the GFRP-GFRP slip-critical connections, based on the adhesion theory of friction for this type of connection, was discussed. Based on the experimental and theoretical analysis of test results, the following conclusions can be drawn:

(1) The slip factor of the G-S24\# connection with grit-blasting treatment stainless-steel cover plates can steadily reach 0.45 ; this slip factor value could satisfy the requirements of engineering applications. The main component of the friction force with the GFRP-GFRP slip-critical connections was likely the deformation force. A large deformation force could steadily transfer the force between the stainless-steel cover plates and GFRP plates. The grit-blasting surface treatment increased the number of asperities and roughness on the faying surface of stainless-steel cover plates and increased the deformation force. The grit-blasting surface treatment of the GFRP plate could damage the mechanical performance of GFRP plate and the slip factor increase can be small; therefore, the grit-blasting surface treatment of the GFRP plate should be avoided.

(2) The slip factor changed with the variation in the prevailing torque effects of the G-S24\# connection. When the prevailing torque equaled $6 \mathrm{~N} \cdot \mathrm{m}$, the maximum slip factor of $0.45 \mathrm{occurred}$. The prevailing torque was not large. A large prevailing torque can flatten the asperities and reduce the deformation force. The reduction in the deformation force caused the slip load reduction.

(3) Compared to the G-G connection, the G-S24\# connection demonstrated good long-term slip resistance. The residual rate of the slip load of the G-S24\# connection was $91 \%$ after 30 days of preloading time. The mechanical performance of the G-S24\# connection can be relied upon over the service life by considering the relaxation effect. 
Author Contributions: Formal analysis, Y.P.; software, J.Z.; supervision, J.D.; validation, Y.P.; writing-original draft, Y.P., Z.W.; writing-review and editing, Y.P., W.C. All authors have read and agreed to the published version of the manuscript.

Funding: Project of National Natural Science Foundation of China: 51408307 and Project of Nanjing Gongda Construction Technology Co., Ltd.: 2019RD06.

Acknowledgments: This research was funded by Project of National Natural Science Foundation of China grant number [51408307] and Project of Nanjing Gongda Construction Technology Co., Ltd. grant number [2019RD06].

Conflicts of Interest: The authors declare no conflict of interest.

\section{References}

1. Mosallam, A.S. Design Guide for FRP Composite Connections; American Society of Civil Engineers: Palo Alto, CA, USA, 2011; ISBN 978-0-7844-0612-0.

2. Coelho, A.M.G.; Mottram, J.T. A review of the behaviour and analysis of bolted connections and joints in pultruded fibre reinforced polymers. Mater. Des. 2015, 74, 86-107. [CrossRef]

3. Feo, L.; Latour, M.; Penna, R.; Rizzano, G. Pilot study on the experimental behavior of GFRP-steel slip-critical connections. Compos. Part B Eng. 2017, 115, 209-222. [CrossRef]

4. Mottram, J.T.; Lutz, C.; Dunscombe, G.C. Aspects on the behavior of bolted joints for pultruded fiber reinforced polymer profiles. In Advanced Polymer Composites for Structural Applications in Construction; Hollaway, L.C., Chryssanthopoulos, M.K., Moy, S.S.J., Eds.; Woodhead publishing limited: Cambridge, UK, 2004; pp. 384-391. ISBN 1-85573-736-7.

5. Hashimoto, K.; Sugiura, K. Mechanical consideration on frictional behavior and maximum strength of GFRP members connected by high strength frictional bolted joint. J. Struct. Eng. 2012, A 58A(0), 935-945. (In Japanese)

6. Stranghöner, N.; Afzali, N.; De Vries, P.; Schedin, E.; Pilhagen, J. Slip factors for slip-resistant connections made of stainless steel. J. Constr. Steel Res. 2019, 152, 235-245. [CrossRef]

7. Quinn, J.A. Composites-Design Manual, 3rd ed.; James Quinn Associates Ltd.: Liverpool, UK, 2002; ISBN 0-9534654-1-1.

8. Mottram, J. Friction and load transfer in bolted joints of pultruded fibre reinforced polymer section. In FRP Composites in Civil Engineering - CICE 2004; CRC Press: Boca Raton, FL, USA, 2004; pp. 845-850.

9. European Committee for Standardization. BS EN 1090-2:2008+A1, Execution of Steel Structures and Aluminium Structures-Part 2: Technical Requirements for Steel Structures, vol. 1; European Committee for Standardization: Brussels, Belgium, 2011.

10. RCSC. Specification for Structural Joints Using High-strength Bolts; Research Council on Structural Connections: Chicago, IL, USA, 2009.

11. SAI Global Limited. AS 4100-1998 (R2016) Steel Structures; Standards Australia, SAI Global Limited: Sydney, Australia, 2016.

12. Lacey, A.; Chen, W.; Hao, H.; Bi, K. Experimental and numerical study of the slip factor for G350-steel bolted connections. J. Constr. Steel Res. 2019, 158, 576-590. [CrossRef]

13. Akinlabi, E.T.; Akinlabi, S.A.; Ogunmuyiwa, E. Characterizing the effects of sand blasting on formed steel samples. Int. Sch. Sci. Res. Innov. 2013, 7, 2216-2219.

14. Bouledroua, O.; Meliani, M.H.; Azari, Z.; Sorour, A.A.; Merah, N.; Pluvinage, G. Effect of Sandblasting on Tensile Properties, Hardness and Fracture Resistance of a Line Pipe Steel Used in Algeria for Oil Transport. J. Fail. Anal. Prev. 2017, 17, 890-904. [CrossRef]

15. Kobayashi, K.; Hino, S.; Yamaguchi, K.; Ohmoto, T. Experimental study on strength of GFRP and steel plates connection using adhesively-bonded and bolted joint. J. Struct. Eng. 2009, 55A, 1140-1149. (In Japanese)

16. Van De Hulst, H.C.; Twersky, V. Light Scattering by Small Particles. Phys. Today 1957, 10, 28. [CrossRef]

17. Heistermann, C.; Veljkovic, M.; Simões, R.; Rebelo, C.; Da Silva, L.S. Design of slip resistant lap joints with long open slotted holes. J. Constr. Steel Res. 2013, 82, 223-233. [CrossRef]

18. Association for Engineering Construction Standardization CECS 410: 2015. Technical Specification for Stainless-Steel Structures; China Association for Engineering Construction Standardization: Beijing, China, 2015. (In Chinese) 
19. JGJ 82-2011. Technical Specification for High Strength Bolt Connection of Steel Structures; Ministry of Housing and Urban Rural Development of the People'S Republic of China: Beijing, China, 2011. (In Chinese)

20. Chen, Z.; Peng, Y.; Su, W.; Qian, F.; Dong, J. Experimental investigation for anti-slipping performance of stainless steel slip-resistant connections with particles embedded in connected plates. Constr. Build. Mater. 2017, 152, 1059-1067. [CrossRef]

21. International Organization for Standardization. ISO 3506-1:2009(E), Mechanical Properties of Corrosion-Resistant Stainless-Steel Fasteners _Part 1: Bolts, Screws and Studs; ISO: London, UK, 2009.

22. Xie, M.J. Connection of Composite Materials; Shanghai Jiaotong University Press: Shanghai, China, 2011; ISBN 9787313163998. (In Chinese)

23. Wang, Y.Q.; Guan, J.; Zhang, Y.; Yang, L. Experimental research on slip factor in bolted connection with stainless-steel. J. Shenyang Jianzhu Univ. 2013, 29, 769-774. (In Chinese)

24. Jonathan, H.E. Creep and mechanical properties of carbon fibre reinforced PEEK composite material. Master's Thesis, University of Manitoba, Winnipeg Manitoba, MB, Canada, 10 October 1992.

25. Wu, C.; Bai, Y.; Mottram, J.T. Effect of Elevated Temperatures on the Mechanical Performance of Pultruded FRP Joints with a Single Ordinary or Blind Bolt. J. Compos. Constr. 2016, 20, 04015045. [CrossRef]

26. Bhushan, B. Introduction to Tribology; Wiley: Columbus, OH, USA, 2013.

27. Li, S.; Hu, J.; Ren, H. The Combined Effects of Environmental Conditioning and Sustained Load on Mechanical Properties of Wet Lay-Up Fiber Reinforced Polymer. Polymer 2017, 9, 244. [CrossRef] [PubMed]

(C) 2020 by the authors. Licensee MDPI, Basel, Switzerland. This article is an open access article distributed under the terms and conditions of the Creative Commons Attribution (CC BY) license (http://creativecommons.org/licenses/by/4.0/). 